\title{
midiätica@)
}

\section{Super-homens da América: \\ por que precisamos falar sobre os quadrinhos de super-heróis?}

\author{
Supermen of America: \\ why do we need to talk about super-heroes?
}

\author{
Francisco de Assis NASCIMENTO ${ }^{1}$ \\ Luis Paulo PIASSI ${ }^{2}$
}

\begin{abstract}
Resumo
Através de uma revisão do panorama histórico-social dos Estados Unidos nos anos 1920, 1930 e 1940, investigamos o surgimento da indústria das Histórias em Quadrinhos de super-heróis através de seu panorama social. Este artigo analisa como a realidade estadunidense foi transposta pelos jovens artistas responsáveis pelo surgimento dos super-heróis para dentro da nova mídia de entretenimento juvenil que criaram, uma transposição que não se limitou a replicar um discurso de interesses políticos econômicos, representando nas páginas daqueles Quadrinhos modelos de comportamento tidos como ideal para o homem naquela sociedade, influenciando a construção da identidade de gênero de seus leitores até os dias atuais.
\end{abstract}

Palavras-chave: Histórias em Quadrinhos. Superman. Gênero. Identidade.

\begin{abstract}
This paper a analyses the historical-social panorama off 1920's America, when the comic book industry of Superheroes has arrived, through one of it's most famous character, the Superman. The article goal is to investigate how social reality is represented by artists in a youth entertainment media, a representation that is not limited to economic political views: the Superheroes Comics presents to its reader the ideal models for gender behavior in that society, which influences the construction of the gender identity of its readers until the present day.
\end{abstract}

Keywords: Superman. Gender. Comic Books. Identity.

\footnotetext{
${ }^{1}$ Doutor em Educação (2017) pela Faculdade de Educação da USP. Professor da Escola de Engenharia e Ciências Exatas da Universidade Anhembi-Morumbi. Membro do Grupo de Pesquisas INTERFACES (Interfaces e Núcleos Temáticos de Estudos e Recursos da Fantasia nas Artes, Ciências, Educação e Sociedade) e do Projeto Banca da Ciência da Escola de Artes, Ciências e Humanidades da USP.

E-mail: francisco.assis@usp.br

${ }^{2}$ Doutor em Educação pela Faculdade de Educação da USP. Professor Associado da Escola de Artes, Ciências e Humanidades da USP. E-mail: Lppiassi@usp.br
} 


\section{midiática@ę)}

\section{Introdução}

O Super-homem, atualmente publicado no Brasil com seu nome original em inglês, Superman, pode ser considerado o maior expoente das Histórias em Quadrinhos de Super-Heróis, um meio de comunicação em massa que tem se expandido cada vez mais em nossa sociedade. Ao alcançar um número cada vez maior de consumidores, como qualquer mídia, seu discurso pode ser bem ou mal-usado, por isto é entender o que ele pode representar para o universo juvenil e adulto de sua audiência.

A partir de sua riqueza simbólica, as Histórias em Quadrinhos de Super-Heróis transmitem aos seus leitores representações de suas próprias necessidades através de modelos de comportamento idealizados em suas narrativas por meio de conflitos humanos profundos, com angústias e temas como a necessidade em ser amado ou o medo da discriminação social. Entretanto, a leitura dessas Histórias não trata de uma contemplação passiva da realidade modelada, mas de uma expressão da atividade humana da busca pelo sentido em sua própria vida, sobre a qual esclarece Tardeli:

[..] relaciona-se a poder perceber-se como alguém satisfeito consigo mesmo e com o que faz ou com o que pode vir a fazer no futuro - ter um projeto de vida. Esses sentimentos positivos dão força para o desenvolvimento cognitivo e emocional, além de possibilitar o enfrentamento das adversidades com as quais, inevitavelmente, todos se deparam. (TARDELI, 2011, p. 121)

Desde seu surgimento como mídia de comunicação em massa, as Histórias em Quadrinhos apresentam como característica a representação, em seu universo ficcional, de visões da realidade que cerca sua esfera de produção: a primeira tira em quadrinhos brasileira, de autoria de Ângelo Agostini, era intitulada “As aventuras de Nhô Quim" e foi publicada em 1869 pelo jornal "Vida Fluminense", retratando a vida na côrte do Rio de Janeiro; a estadunidense "Down Hogan's Alley" de Richard F. Outcalt, estreou sua sátira da vida dos imigrantes nos cortiços de Nova York nas páginas do jornal norteamericano New York World, em 1885: ambas as narrativas podem ser consideradas uma expressão do contexto histórico em que eram produzidas.

Os Super-Heróis surgiram em 1938, no decorrer da chamada "Era de Ouro" dos Quadrinhos, um período histórico contemporâneo a quebra da bolsa de Nova York 


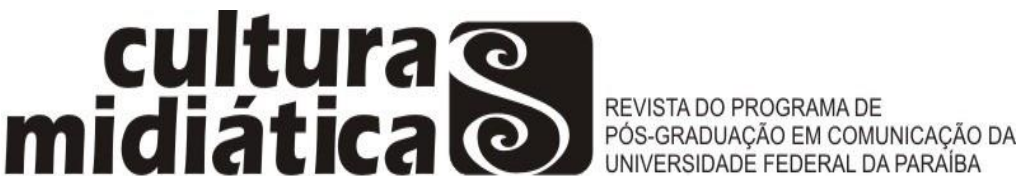

(1929) e ao "Neaw Deal", projeto de reestruturação da economia estadunidense que delimitou o desenvolvimento da trajetória iniciada com a publicação da primeira tirinha em quadrinhos das aventuras de Tarzan dos Macacos em 1928.

No ano de 1929 os adolescentes Jerry Siegel e Joseph Schuster iniciaram uma jornada de aperfeiçoamentos no personagem criado para protagonizar o conto que publicaram no fanzine "Science Fiction" \#3 em seu colégio, uma historia chamada "The Reign of the Superman"3.

Figura 1: a primeira versão do Superman era um vilão, e não um herói. Entretanto, pontos como os superpoderes e a identidade secreta já estavam presentes nessa versão. ${ }^{4}$

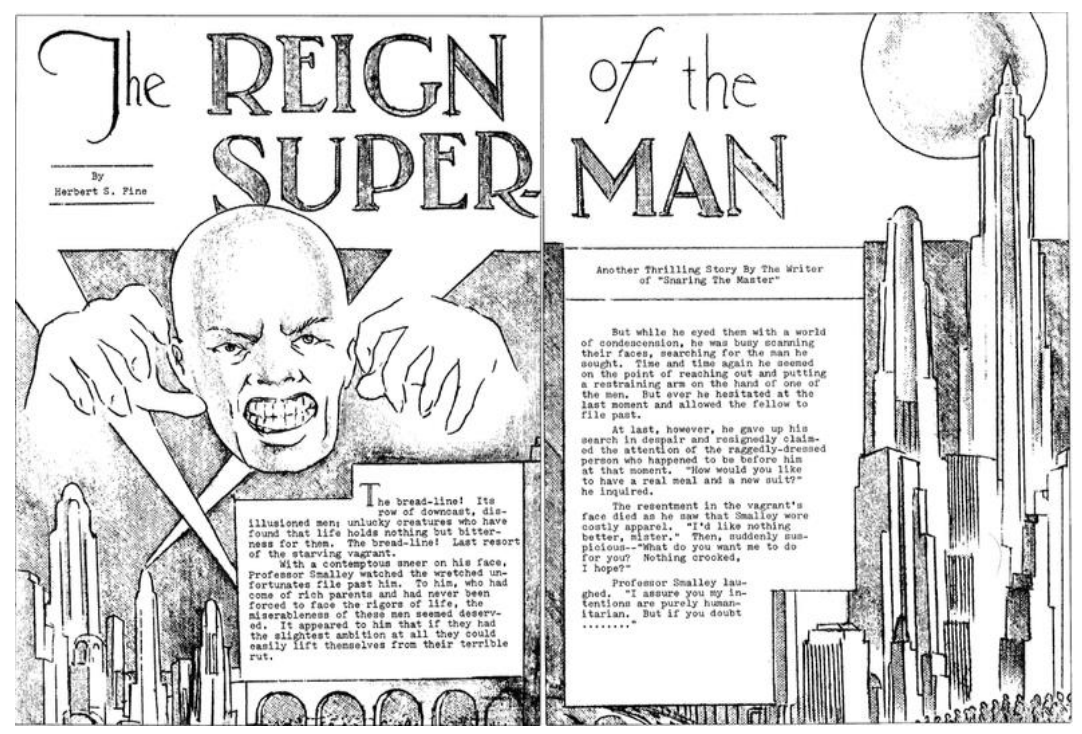

O conto, ilustrado por Schuster, narrava a aventura de um vilão de traços intrincados, um viajante do tempo com poderes mentais sobre-humano chamado "Superman", em uma cidade futurística desenhada a partir do design industrial. Em 1938, quando a revista Action Comics \#1 apresentou ao público a versão reformulada de Siegel e Shuster para seu Superman, a edição foi um sucesso instantâneo de vendas que levou outras editoras de Histórias em Quadrinhos e literatura Pulp a desejar

\footnotetext{
3 “O Reinado do Super-Homem”, em tradução livre.

4 Disponível em:

https://upload.wikimedia.org/wikipedia/commons/thumb/3/34/Reign_of_the_Superman.jpg. Acesso em $28 / 09 / 2017$
} 


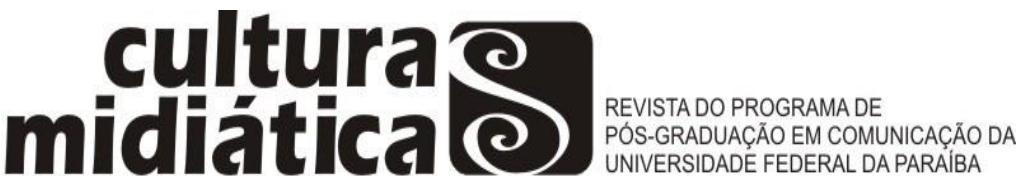

imediatamente uma fatia do novo mercado consumidor que viram surgir (NASCIMENTO, 2017).

A editora National Periodics não foi a única para a qual Siegel e Schuster apresentaram sua criação. Quando foi finalmente aceito para publicação, o personagem já havia passado por praticamente todas as mesas de editores de Quadrinhos de Nova York. Em sua biografia de Will Eisner, Michael Schumacher (2013) revela como o autor considerou a relutância das editoras em publicar o personagem uma decorrência do período histórico que atravessavam, marcado pela ascensão de Adolf Hitler ao poder na Alemanha:

Estávamos todos preocupados com o esquema dos nazis, com os conceitos nazistas. Mein Kampf foi publicado aqui em 1935, e falavase muito desse conceito de Super-Homens. O impacto psicológico dessas ideias no pessoal que criava fantasia era imenso. (EISNER apud SCHUMACHER, 2013, p. 62)

A proposta de entretenimento juvenil das Revistas de Histórias em Quadrinhos de Super-Heróis nasceu já influenciada de forma decisiva pelo momento ideológico de sua produção. O sucesso comercial de Action Comics \#1 iniciou uma época em que o sucesso de vendas dos super-heróis os levou a dominar as publicações de revistas de Histórias em Quadrinhos. Nesta fase também surgiram personagens como Aquaman, Mulher-Maravilha, Batman, Capitão América, Namor e Tocha Humana, hoje tidos como clássicos da indústria, na esteira do sucesso comercial que Schumacher (2013) analisa de modo incisivo:

A Action Comics não apenas se deu bem nas bancas; ela foi uma explosão de vendas que começou com força e, nos meses seguintes, transformou-se em uma bola de neve até se tornar o padrão da indústria para o florescente mercado de quadrinhos de Super-Heróis. (SCHUMACHER, 2013, p. 64) (grifo nosso).

Desde sua origem, os Quadrinhos inspiram o nascimento de uma cultura que se adapta e integra ao contexto histórico de sua produção, expressando anseios, valores, preconceitos e frustrações de seus criadores, eles mesmo produtos de sua época e lugar. Nos quadrinhos estão as representações do real, ou daquilo que o autor deseja mostrar como realidade. 


\section{midiätica@e}

Protegidos pela tinta e pelo papel, os personagens das histórias em quadrinhos materializam representações que são constantemente retomadas, reatualizadas e normatizadas sob a forma de um simples exercício de leitura; do jogo lúdico entre palavra e imagem, que aparentemente desvinculado do mundo real, retoma, recria e fundamenta modelos e saberes. (OLIVEIRA, 2007, p. 23)

Dentro dessa perspectiva, os Quadrinhos constituem um espaço de representação social, dos cenários aos enredos, seus constituintes podem ser vistos como apropriações imaginativas de conceitos, valores e elementos que refletem a realidade do período histórico de sua produção.

As normas de comportamento incluem não apenas o discurso político e ideológico, mas também as diferentes formas de ser homem e ser mulher aceitas pela sociedade de seu tempo. E, se até o final do século XX as Histórias em Quadrinhos de Super-Heróis foi um produto destinado majoritariamente ao público masculino, encontraremos em sua origem o modelo do Homem visto como ideal para aquela época, um modelo repaginado a cada mudança histórica percorrida pela Indústria dos Quadrinhos na segunda metade do século XX e que pode ser analisado através do personagem Superman.

Sua representação dos diferentes papéis de gênero transmitem as visões e anseios de uma sociedade em relação ao comportamento do sujeito, o que nos permite compreender algumas das relações de conflito identitário presentes em nossa sociedade atual pelo estudo de sua origem.

\section{A Questão de Gênero}

Ao voltarmos nossa atenção para a questão de gênero, encontramos na representação binária dos papéis um ponto fundamental para o surgimento da indústria das Histórias em Quadrinhos de Super-Heróis, uma mídia baseada na construção de uma cultura a partir da apresentação de papéis performáticos para o masculino e o feminino, apresentados como únicos e hierarquizados entre si.

Há um longo recorte a ser feito para a contextualização dos estudos de gênero, desde o final do século XIX quando cientistas e estudiosos passaram a contestar o entendimento do termo como de natureza fixa, autêntica e traçada exclusivamente a partir do caráter biológico do sexo. Essa designação binária consiste em uma abordagem 


\section{midiätica@e}

limitada e reducionista que fortalece o discurso político e ideológico de normatização da visão naturalizada da heteronormatividade.

Trata-se de uma concepção para gênero em desacordo com os estudos desenvolvidos no decorrer do século XX: para Judith Butler (2010) a questão gênero deve ser compreendida como expressão fluída e performática, não sendo possível ao sujeito ser homem ou ser mulher em uma visão pautada unicamente a partir de seu sexo biológico, uma vez que no processo de nossa construção identitária somos mais ou menos propensos a adotar determinados padrões performáticos para encenar gênero a partir das constantes repetições que nos são apresentadas nas de diferentes esferas de interação social em que nos inserimos, o que inclui os discurso veiculados pela mídia que consumimos.

Se cada grupo social constrói seu entendimento sobre gênero de maneira diferenciada de acordo com sua época e lugar, historiciza-se o que entendemos como "modos de ser" do sujeito, que passam a ser entendidos como relacionais: o atributo de comportamento considerado adequado ao que é considerado masculino ou feminino é detentor de um sentido social, definido pela cultura e delimitado por diferentes critérios classificatórios como raça, religião, gênero e classe econômico-social.

Os Super-Heróis são fruto de uma sociedade heterogênea, o que torna natural que categorias hierarquizadas por essa sociedade assim se apresentem nas narrativas em Quadrinhos.

Para sobreviver no mercado de consumo, toda mídia depende de um público consumidor que se identifique com suas opiniões, sentimentos e disposições que lhes são apresentados. Isto também vale para as Histórias em Quadrinhos de Super-Heróis, levados a propagar uma cultura de massa que seduz o público, formatando-o em audiência. Esse discurso midiático não é inocente, mas permeado por significados e efeitos políticos, como esclarece Kellner (2001, p. 9):

O rádio, a televisão, o cinema e os outros produtos da indústria cultural fornecem os modelos daquilo que significa ser homem ou mulher, bem-sucedido ou fracassado, poderoso ou impotente. A cultura da mídia também fornece o material com que muitas pessoas constroem o seu senso de classe, de etnia e raça, de nacionalidade, de sexualidade, de "nós" e "eles". Ajuda a modelar a visão prevalecente de mundo e os valores mais profundos: define o que é considerado bom ou mau, positivo ou negativo, moral ou imoral. 


\section{midiätica@e}

O autor relaciona a questão da construção identitária com aquilo que chama "pedagogia da mídia”, onde a descoberta e a construção pessoal estão subordinadas aos exemplos do discurso midiático. Kellner (2001) desvela a importância da mídia na formação do sujeito, porque ela ocupa o papel de agente responsável pelo ensinar a ser, qual o modo de pensar e quais as atitudes de comportamento aceitas em sociedade, desempenhando um papel importante na construção da identidade de seu consumidor.

No caso das Histórias em Quadrinhos do Superman, ocorre a hipervalorização de um modelo de performance masculina hierarquizado sobre os demais, em uma relação desigual de poder que Bordieu (1998) pressupõe ser aceito pelos demais grupos subalternos/dominados, ainda que não necessariamente de forma explícita e consciente, podendo se tratar de uma forma de submissão pré-reflexiva. $\mathrm{O}$ autor vê essa questão da dominação masculina como uma forma de violência simbólica, responsável pela manutenção de um poder mascarado nas relações sociais e infiltrado nos pensamentos.

Apesar de não trabalhar o conceito gênero de forma explícita, Bordieu (2002) percorre um percurso em acordo ao trabalho de Butler (2010), afirmando que o contato com o maior número de representações será sempre positivo ao sujeito em formação, fortalecendo sua capacidade de diálogo com o mundo, denunciando o pensamento baseada na dicotomia masculino / feminino afirmando que corpo e biologia são espaços nos quais a desigualdade entre os sexos é naturalizada.

Heteronormativo, branco, monogâmico, Superman é apresentado como personagem filho da Ciência, tendo como pai biológico o maior cientista de seu planeta natal. Em suas aventuras, o personagem luta em prol de um estado de paz e justiça em defesa dos valores da sociedade estadunidense. Com o que poderia ser considerado um discurso de fundo socialista nas 13 páginas de sua aventura de estreia, ele enfrenta a corrupção política do Senado dos Estados Unidos apresentando-se como "herói do povo norte-americano" e não como "defensor do modo de vida norte-americano", como ficaria conhecido ao final do século XX. 


\section{midiätica@e}

[..] o super-herói seria um modelo para as crianças e uma força em prol da justiça no mundo (...) tirava os garotos pobres das garras das gangues e os levava de volta para suas mães e também ensinava algumas lições a moleques atrevidos e depois os despachava, já mais humildes, para ser bons cidadãos. A mensagem no trabalho de Jerry e Joe não tinha um corpo político coerente, mas evocava a prática de governo Roosevelt, era um retrato Hollywoodiano do New Deal. (JONES, 2006, p.143)

Em suas primeiras aventuras o Superman não voava, mas era capaz de saltar sobre os edifícios de sua cidade, parecida com a Nova York dos anos 1930, um mundo ficcional assombrado pelas conhecidas injustiças do mundo real como a tirania, a pobreza, a corrupção política, o desemprego e a violência.

Figura 2: Em sua aventura de estreia, Superman investiga um senador corrupto dos EUA $^{5}$.
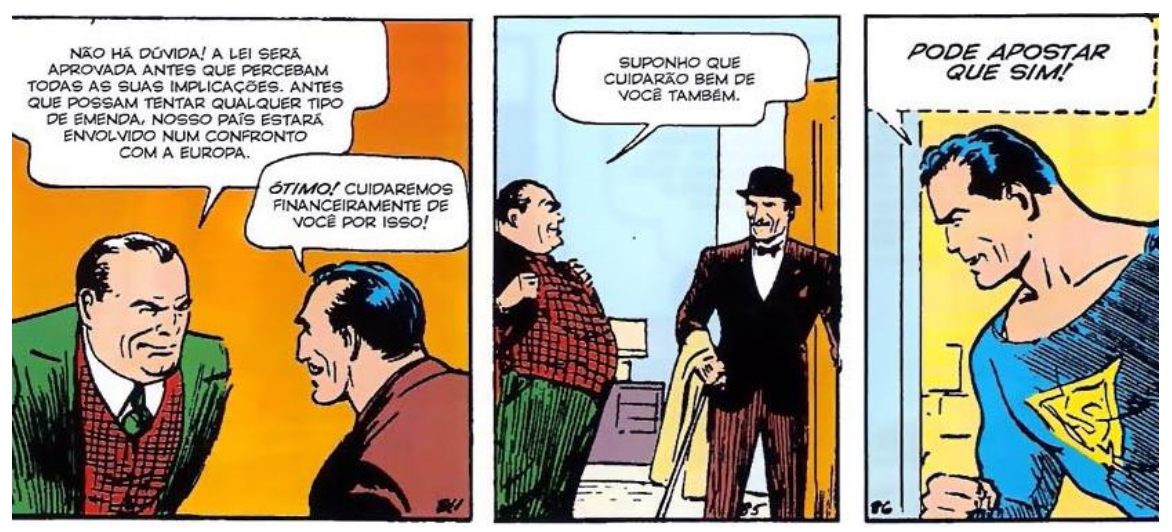

Sua origem e habilidades iniciais são uma releitura do personagem John Carter do conto "Uma Princesa de Marte" publicado em 10 de outubro de 1917 por Edgar Rice Burroughs, uma história que narra as aventuras de um ser humano transportado da Terra à Marte, onde se descobre possuidor de força, resistência e velocidade superiores aos habitantes locais, graças as diferenças físicas entre os dois planetas. Em síntese, as mesmas habilidades sobre-humanas e a mesma justificativa apresentada pelo personagem de Siegel \& Schuster.

\footnotetext{
${ }^{5}$ Disponível em: https://fromcomicstothebigscreen.wordpress.com/top-tens/action-comics-1/
} 


\section{midiätica@e}

Assim como Tarzan e John Carter, Superman não era apenas o mais forte de sua raça, ele também pertencia a uma raça diferente daquela que habitava o local de suas aventuras e era detentor de uma superioridade inata, que lhe permitiria alcançar o comando de qualquer mundo que adentrasse. Do mesmo modo que os laços de Tarzan com a nobreza da Inglaterra e a ligação de John Carter com a antiga Confederação dos Estados da América explicava seu potencial para a superioridade, Superman é apresentado como filho das conquistas da Ciência, personificada na figura de seu pai biológico desde a história de sua origem.

Jor-El é apresentado como um gênio isolado, incompreendido pela sociedade que o cerca, detentor de um conhecimento que se recusa a se submeter a política. Em suas aventuras, Superman deve proteger a Terra de invasões colonizadoras, tecnologicamente superiores, mas socialmente incapazes de lidar com as diferenças entre as raças que compartilham a vida no universo.

Ainda que não haja uma referência direta a obra de Burroughs em seu texto, os autores apresentam ao leitor uma explicação pseudocientífica para os superpoderes do Superman em sua primeira aventura na página 06 da revista Action Comics \#1:

[...] Uma explicação científica da força admirável de Clark Kent. Inverossímil? Não! Porque mesmo hoje, sobre o nosso mundo, existem criaturas com força sobrenatural. A humilde formiga pode suportar peso milhares de vezes maior que o seu. $O$ salto do gafanhoto, comparado à possibilidade humana, equivale ao pulo de vários quarteirões de uma rua. Kent veio de um planeta cujos habitantes tinham uma estrutura física milhões de anos mais avançada que a nossa e que, atingindo a maturidade, eram dotados de força prodigiosa. (SIEGEL, 1938, p.6)

A ficção pulp de Burroughs não foi o único ponto de influência da cultura de massa do início do século XX na construção do personagem. Em sua identidade visual o personagem veste um uniforme desenhado para transmitir uma mensagem de força e agilidade superiores ao de um ser humano comum. Para o escritor Grant Morrison:

(...) o verdadeiro entendimento visual distinto do Superman só veio muito depois, quando descobri fotos dos fortões de circo dos anos 1930. Lá entre as cordas das tendas e carroças pintadas estava a conhecida e levemente perturbadora combinação de cueca-cinto, vestida por homens com bigodes de guidão que erguiam alteres com as mãos grossas e faziam caretas para a câmera. Finalmente fazia 


\section{midiäticale}

sentido. A solução para a maior charada dos Quadrinhos sempre esteve ali no tedioso passado, no qual ninguém se dera ao trabalho de procurar. Cuecas sobre as calças eram significantes de força e resistência ultra masculinas em 1938. As capas, as botas de showman, o cinto e o colante de lycra vinham todos dos uniformes de circo e ajudavam a enfatizar $o$ aspecto performático das aventuras de Superman. (MORRISON, 2012, p. 32)

As Histórias em Quadrinhos de Super-Heróis separam sua trajetória em diferentes “eras” de identificação notória para sua indústria e mercado consumidor, associadas a sua popularidade, desenvolvimento e período histórico em um agrupamento ocorre de modo espontâneo a partir de características comuns a todas as publicações, entre as quais a performance de gênero, responsável pela construção da figura do herói como modelo de comportamento a ser imitado

Como todo produto cultural, suas Histórias em Quadrinhos são fruto de uma época e um lugar, representando a realidade de sua sociedade através do filtro da visão do artista e sua indústria.

[...] Jerry Siegel, Jack Liebowitz, Joe Shuster, Henry Donenfeld, Charlie Ginsberg, Bob Khan, Stanley Lieber, Jake Kutzberg, Mart Weisinger: todos da mesma geração, conhecidos entre si, todos garotos judeus, filhos de imigrantes (...) muitos desses jovens não tinham pais, seja no aspecto físico ou emocional. Muitos deles não tiveram a oportunidade de ser criados de forma mais apropriada e foram forçados a assumir o papel de adulto muito cedo(...) as relações que mantinham com a masculinidade, a sexualidade, o poder, a individualidade, a violência, a autoridade eram tão intrinsicamente profundas que seu trabalho falava diretamente às ansiedades da vida moderna. (JONES, 2006, p. 19)

O pai de Jerry Siegel foi assassinado em 1932 e, talvez não por coincidência, sua criação seja uma figura paterna à prova de balas que combatente o crime. Para os autores responsáveis pelo surgimento dessa indústria, a figura do herói deveria ser representada pelo indivíduo capaz de zelar pela ética do trabalho, como meio de fortalecer a economia de sua sociedade e os vilões são aqueles que, de alguma forma, violam o pacto de reestruturação da nação: políticos corruptos, assaltantes de bancos e ladrões comuns. 


\section{midiaturąe \\ REVISTA DO PROGRAMA DE \\ PÓS-GRADUAC̄ÃO EM COMUNICAÇ̃̃O DA \\ UNIVERSIDADE FEDERAL DA PARÁIBA}

Figura 3: Em sua identidade secreta como repórter, Superman investiga a corrupção na política de seu país ${ }^{6}$.

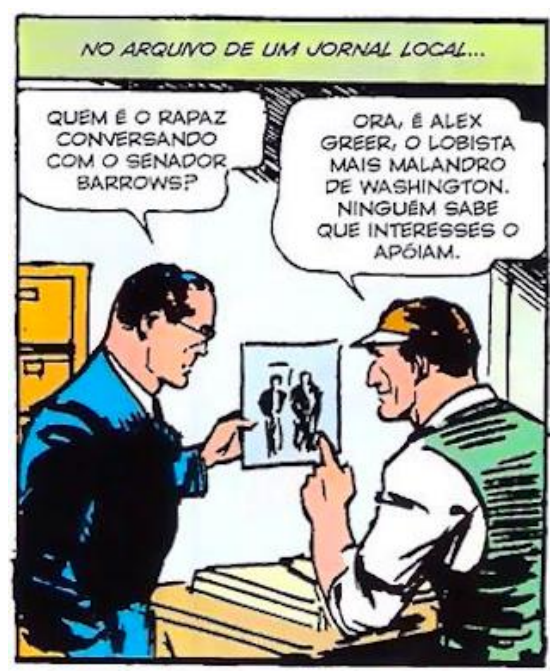

Pouco depois, com o levante da 2 Guerra Mundial, o herói assumiria um novo papel, o de patriota militarizado, personificando o homem capaz de superar o inimigo e trazer a paz, protegendo o status quo de sua sociedade.

Figura 4: Superman enfrenta a força aérea alemã, captura Hitler e em seguida, Stálin, encerrando a 2 Guerra Mundial ${ }^{7}$.

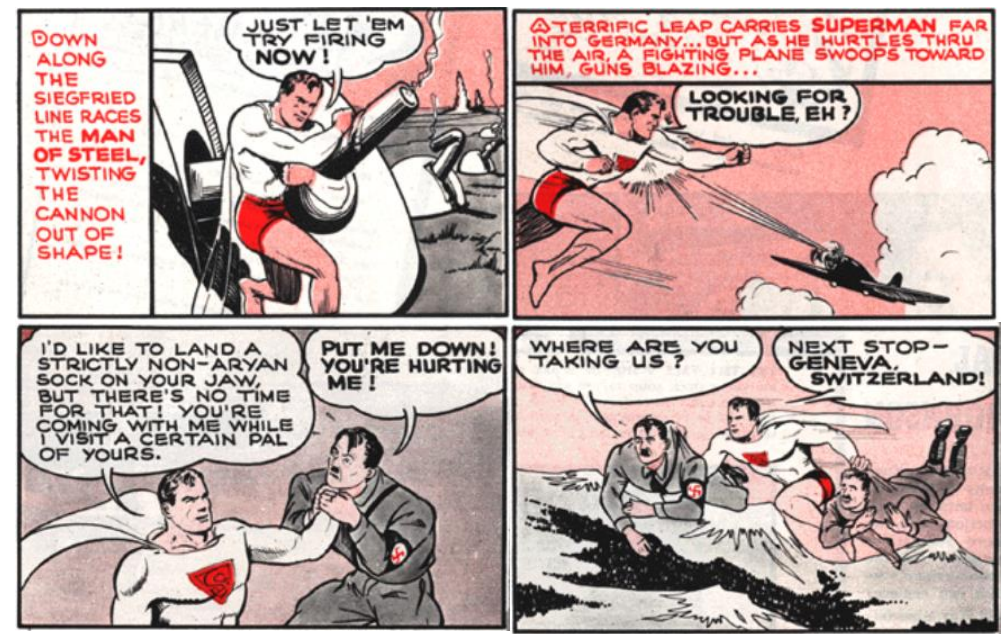

\footnotetext{
${ }^{6}$ Disponivel: https://fromcomicstothebigscreen.wordpress.com/top-tens/action-comics-1/

7 Disponível: http://sequart.org/magazine/23691/on-how-superman-would-win-the-war/how-supermanwould-end-the-war-look-magazine/
} 


\section{midiática@ę)}

O Superman se dedica a "alcançar um estado de Justiça e Paz" defendendo os valores da sociedade norte-americana que representa, mas por não lutar por uma condição de igualdade e justiça social ele se limita a batalhar pela manutenção da Lei e do combate a crimes contra a propriedade privada.

Ainda que defenda a proteção da integridade humana contra manifestações violentas, é preciso ressaltar que essas manifestações também incluem a reação dos oprimidos contra a política opressora, causa da desigualdade social. O personagem luta pelo resgate de um passado a ser restabelecido como presente contínuo, pela hegemonia de determinados setores de sua sociedade sobre as demais.

Seus aparentemente ilimitados superpoderes não estavam presentes em sua criação. Sua evolução ocorreu a partir dos anos 1950 e pode ser compreendida como uma justificativa cultural para a própria existência do personagem frente aos avanços da URSS no decorrer da chamada "corrida espacial": para ser reconhecido como "Super", ele deveria possuir capacidade de ação a frente das possibilidades tecnológicas da superpotência rival.

\section{Contexto histórico}

De acordo com a dialética marxista, é a partir das condições materiais de existência que os homens se organizam, criam leis e costumes, estabelecendo relações em torno da noção de trabalho e o homem produz sua própria realidade social através das condições materiais existentes "Não é a consciência do homem que lhe determina o ser, mas, ao contrário, o seu ser social que lhe determina a consciência”. (1978, p. 130) e é o caminho que Eric Hobsbawn (1996) seque para apontar o entendimento da forte relação entre a perda de poder político por uma sociedade dominadora em essência devido a uma crise econômica e a ascensão de produtos culturais com o objetivo de recuperar sua autoestima.

Embora o historiador adote o Império Britânico dos anos 1960, o mesmo pode ser extendido ao surgimento dos Super-Heróis nos Estados Unidos dos anos 1930: 


\section{midiätica@e}

A Guerra Fria que de fato tento corresponder à sua retórica de luta pela supremacia ou aniquilação não era aquela em que decisões fundamentais eram tomadas pelos governos, mas a nebulosa disputa entre seus vários serviços secretos reconhecidos e não reconhecidos, que no Ocidente produziu esse tão característico subproduto da tensão internacional, a ficção de espionagem e assassinato clandestino. Nesse gênero, os britânicos, com o James Bond de Ian Fleming e os heróis agridoces de John le Carré - ambos tinham trabalhado nos serviços secretos britânicos -, mantiveram uma firme superioridade, compensando assim o declínio de seu país no mundo do poder real. (HOBSBAWN, 1996, p. 226)

O autor relaciona a gênese de produtos culturais voltados ao fortalecimento de uma visão de perda social causada pela perda do poder político real, colocando esta como a origem daquela numa tentativa da ficção de fortalecer a identidade das nações cujo papel de destaque no jogo de poder global se via diminuído.

As Histórias em Quadrinhos de super-heróis eram um divertimento barato e descartável, bastante popular entre os jovens norte-americanos entre as décadas de 1930 e 1950. Segundo Jones (2006), aproximadamente $85 \%$ das crianças norte americanas em idade escolar daquela época adquiriu o hábito de leitura destas revistas, um hábito que mantiveram ao ingressar na idade adulta, mesmo quando enviados como soldados para lutar na Segunda Guerra mundial.

Os super-heróis anteciparam e concretizaram o anseio de intervencionismo e influência mundial almejado pelo cidadão norte-americano, levando-se em conta que grande parte da indústria produtora dos Quadrinhos possuía ascendência judaica e um interesse direto no conflito. A participação na Segunda Guerra Mundial representou para os Estados Unidos o fim de uma crise que se iniciou com a queda da Bolsa de Nova York, em 1929, e seu retorno ao papel de potência econômica mundial.

Nesta época, o Superman representava o elo que unia dois públicos distintos: para as crianças, uma forma de se sentir parte do esforço de Guerra através de um exercício de imaginação estimulado pelas aventuras que liam. Para os soldados no front de batalha, o contato com o ambiente doméstico deixado para trás, ajudando a diminuir as saudades de casa enquanto fortalecia sua moral e auto estima. 


\section{midiătica@

Figura 5: Já em seu uniforme clássico, o Superman incorpora mais uma categoria a sua performance de gênero: o patriota militarizado ${ }^{8}$.
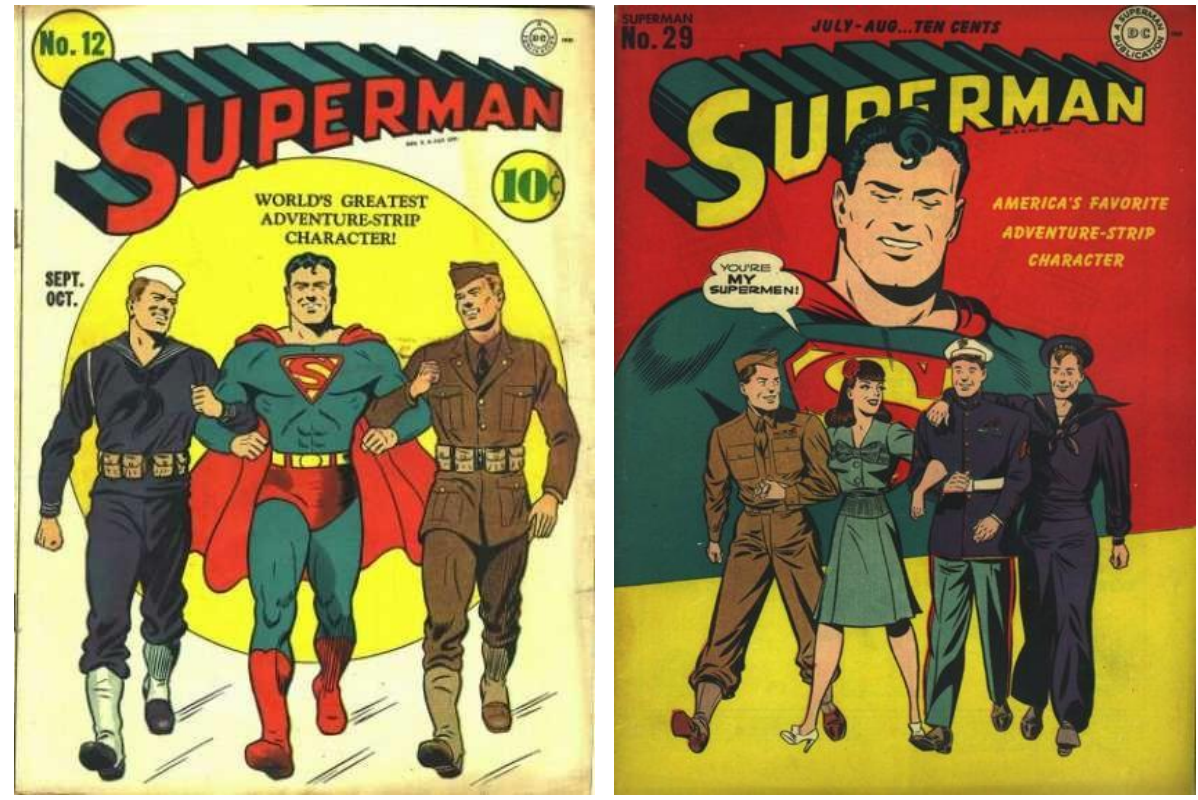

Em 1954, a publicação do livro "Seduction of the Innocents" pelo psiquiatra e crítico social alemão Fredric Wertham, alertava a sociedade norte-americana para um "perigo social" representado pela leitura de revistas de Quadrinhos. Para o autor, as revistas seriam não apenas uma "forma ruim de literatura", mas também um fator decisivo no aumento da delinquência juvenil, o que levou o Congresso dos Estados Unidos a realizar uma série de audiências, e acarretou o declínio na popularidade dos Super-Heróis.

Wertham (1954) fez a paranoica sociedade norte-americana dos anos McCarthy pensar os quadrinhos de super-heróis como corruptores de suas crianças, dando origem a uma caça às bruxas a cada possível sinal do que o autor pudesse interpretar como depravação.

Em 1956, comparadas com as dúzias que existiam na década de 1940, poucas editoras de revistas em quadrinhos haviam sobrevivido a perseguição moralista do

\footnotetext{
8 Disponivel: http://sequart.org/magazine/23691/on-how-superman-would-win-the-war/superman-vol-1$29 /$
} 


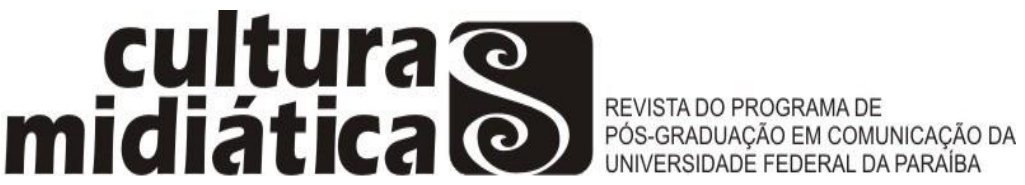

Congresso Norte-Americano, marcando o fim da Era de Ouro das revistas de Histórias em Quadrinhos de Super-Heróis.

Nos anos que se seguiram, os avanços da ciência aceleraram a corrida armamentista em meio as feridas sociais causadas pelo Macartismo enquanto o movimento pelos direitos civis se tornou cada vez mais forte, com milhares de pessoas protestando pela igualdade de direitos para os afro-americanos e demais minorias.

Jovens estadunidenses, filhos da primeira geração de leitores do Superman, passaram a questionar as políticas de governo de seu país, que iniciava o envolvimento nos conflitos do Vietnã. Esse tumultuado período social não deixou de imprimir sua marca na cultura de massa através de filmes, programas de TV e música, mas as revistas em Quadrinhos demoraram a refletir as mudanças que estavam ocorrendo no modo de vida da sociedade, o que só veio acontecer no decorrer do período que ficou conhecido como "a Era de Prata".

\section{Considerações finais}

Neste trabalho exploramos a relação gênero/sociedade nas Histórias em Quadrinhos do Superman, uma relação profunda que contribui para a manutenção dos estereótipos de gênero na visão de mundo de seus leitores/consumidores. Isto é diferente de dizer que o personagem possa ser considerado o principal responsável por sua instituição, o que não é possível afirmar a partir de nossos estudos.

O que afirmamos é que as Histórias em Quadrinhos do Superman da "Era de Ouro" contribuíram para a perpetuação desses estereótipos, o que faz de sua análise um ótimo ponto de partida para um processo de desconstrução, evidenciando a importância das discussões sobre gênero e mídia em todos os espaços em que ocorram as relações sociais, incluindo o espaço escolar. Consideramos que compreender as relações de gênero que permeiam o cotidiano de nossa sociedade é o primeiro passo para desenvolver uma consciência crítica a respeito de nossa própria identidade, de quem somos e por quê assim somos.

É uma leitura que leva a crer nos moldes da democracia estadunidense como única instituição de governo legítima e na naturalização do sofrimento humano dentro do capitalismo, um discurso falacioso que ignora as diferentes estruturas de poder 


\section{midiäticale}

econômico de uma sociedade, uma concepção reducionista quanto o argumento binário para gênero.

Tem-se a questão gênero fortemente presente nos Quadrinhos de Super-Heróis, baseada no comércio de produtos culturais constituídos a partir da representação de papéis performáticos para a masculinidade e a feminilidade, sobrepostos aos demais possíveis e hierarquizados entre si. São produtos que atribuem uma soberania na escala de poder social à performance homem/branco/heterossexual e fortalece a essência do conceito heteronormativo, onde o ser homem cisgênero heterossexual recebe uma posição de poder sobre as demais performances.

O estudo da cultura das histórias em quadrinhos nos serve como caminho para o entendimento de como um processo cultural é criado através da formação de vínculos e participação dos indivíduos, contribuindo para a criação de uma identidade própria para a sociedade em um determinado período histórico, reflexo da construção identitária de seus sujeitos.

\section{Referências}

BOURDIEAU, P. A dominação masculina. Rio de Janeiro: Bertrand Brasil, 2002.

BUTLER, J. Problemas de gênero: feminismo e subversão da identidade. Rio de Janeiro: Civilização Brasileira, 3. ed., 2010.

CYRNE, M. A explosão criativa dos Quadrinhos. Petrópolis: Vozes, 1970.

HOBSBAWN, E. Era dos extremos: o breve século XX. Editora Companhia das Letras, 1996.

JONES, G. Homens do amanhã. Tradução de Guilherme da Silva Braga e Beth Vieira. São Paulo: Conrad Editora do Brasil, 2006, 446 p.

MARX, K. Para a crítica da economia política. In: Marx - Os pensadores. Tradução de José Carlos Bruni (et al). 2. ed. São Paulo: Abril Cultural, 1978, p.103-132.

NASCIMENTO, F. e PIASSI, L.P. Crise de identidade: gênero e ciência nos quadrinhos de super-heróis. Tese (Doutorado) -Faculdade de Educação da Universidade de São Paulo. São Paulo: Universidade de São Paulo, 2017.

OLIVEIRA, S. R. N. Mulher ao quadrado: as representações femininas nos quadrinhos norte-americanos: permanências e ressonâncias (1895-1990). Brasília: Editora Universidade de Brasília. Finatec, 2007. 


\section{midiätica@e}

SCHUMACHER, M. Will Eisner: um sonhador dos quadrinhos. São Paulo: Biblioteca Azul. 424p. 2013

SIEGEL, J; SHUSTER, J. Action Comics (1938), "Superman", New York: Action Comics, 1938. 1-13 p.

TARDELI, D. Super-Heróis na construção da Personalidade in Super-Heróis, Cultura e Sociedade: aproximações multidisciplinares sobre o mundo dos quadrinhos. Nildo Viana / Andréas Reblin (Org.). Aparecida, SP: Idéias \& Letras, 2011.

\section{Consultas}

THE SEQUART ORGANIZATION.

http://sequart.org/magazine/23691/on-how-superman-would-win-the-war/supermanvol-1-29/. Acesso em: 28/09/2017

HOW SUPERMAN WOULD WIN THE WAR?

http://sequart.org/magazine/23691/on-how-superman-would-win-the-war/howsuperman-would-end-the-war-look-magazine/ Acesso em 28/09/2017 